\title{
Comparison of Chloride-Induced Corrosion of Microsilica and ECC in the Offshore Piers' Concrete (Case Study: Wharves P3 \& P4 of Imam Khomeini Petrochemical)
}

\author{
Abdolreza Tangtakabi ${ }^{*}$, Mohammad Hasan Ramesht ${ }^{*}$, Ali Golsoorat Pahlaviani \\ Department of Civil Engineering, Islamic Azad University, Central Tehran Branch, Tehran, Iran \\ Email address: \\ reza.takabi43@gmail.com (M. H. Ramesht) \\ ${ }^{*}$ Corresponding author \\ To cite this article: \\ Abdolreza Tangtakabi, Mohammad Hasan Ramesht, Ali Golsoorat Pahlaviani. Comparison of Chloride-Induced Corrosion of Microsilica and \\ ECC in the Offshore Piers' Concrete (Case Study: Wharves P3 \& P4 of Imam Khomeini Petrochemical). Engineering and Applied Sciences. \\ Vol. 6, No. 4, 2021, pp. 66-73. doi: 10.11648/j.eas.20210604.11
}

Received: June 4, 2021; Accepted: July 8, 2021; Published: August 2, 2021

\begin{abstract}
The corrosion of reinforcements in the tidal zone leads to significant damage to offshore concrete piers. To overcome such damages, the quality of concrete and its mechanical properties should be improved. The aim of the present study is to identify and evaluate the causes and extent of corrosion observed in piers P3 \& P4 in Imam Khomeini petrochemical. The concrete reinforced by microsilica and the ECC concrete are used to prevent corrosion. Some tests were conducted to determine the conditions of concrete piers in terms of reinforcement corrosion. Then, a reinforcement corrosion intensity test using Potentiostat involving a placement process was used, where the water-to-cement ratio was $38 \%$; superplasticizers was $4 \%$; and microsilica was $10 \%$ and $15 \%$. The microsilica can serve as an alternative to the consumed cement and was measured according to the ASTM standards; Besides, it was exposed to aggressive conditions at different periods, and a concrete compressive strength test was performed. The results show that the compressive strength of concrete with microsilica $15 \%$ is nearly $25 \%$ higher than that of ECC, while for the control specimen, this value is about $42 \%$. Regarding the corrosion intensity, the concrete with microsilica $15 \%$ has the minimum value compare to all three other samples. It is recommended to use this type of concrete to overcome the corrosion problem in piers P3 \& P4 in Imam Khomeini petrochemical.
\end{abstract}

Keywords: Offshore Structures, Reinforcement Corrosion, Microsilica, Wharf, Imam Khomeini Port

\section{Introduction}

Concrete is one of the common engineering materials that have frequently been used over the last 100 years. Experts have always considered this material to construct various structures such as buildings, piers, ports, tanks, bridges, and other various structures [1]. Even today, concrete is used on a wide scale in modern societies and will most probably be employed in the future. It shows excellent mechanical performance, has high durability, and is characterized by its low cost and energy consumption $[2,3]$.

One of the most common causes of destruction in reinforced concrete structures is the deterioration of offshore concrete ones due to reinforcement corrosion under the influence of chloride ions. In recent years, extensive research has been conducted in this field, and corrosion has been dealt with as the most important phenomenon in discussions about the damage threatening concrete structures in an offshore environment. Of course, the existence of unfavorable conditions in these areas reveals the need for repairing the structure and determining their service life. From the point of view of armature corrosion in concrete structures, the conditions determining offshore structures on the Persian Gulf's margin have turned this area into one of the most aggressive ones in terms of both solutes in seawater and their climatic conditions. So far, the concrete structures in the Persian Gulf have inflicted severe damage and high repair costs on the countries in the regions. This situation has come about through the corrosion of buried reinforcement, which is regarded as a severe economic problem. As a result, 
increasing attention has been paid to identifying the causes of reinforcement corrosion, preventing it, and tracing factors contributing to concrete structures' highest strength and durability $[4,5]$.

Bagheri et al. [6] conducted a number of experiments and observed that concrete electrical resistance could increase five times by replacing $12 \%$ microsilica with cement. Pandey and Kumar [7] performed an evaluation on the water absorption, and chloride ion penetration of rice straw ash and microsilica admixed pavement quality concrete. They derived two equations for both the initial and secondary rate of water absorption. Moffat et al. show that, given the same duration and conditions, the performance of concrete which contained fly ash and microsilica exposed to an offshore environment could decrease the depth of chloride penetration from $90 \mathrm{~mm}$ to $40 \mathrm{~mm}$, as against all the control samples which had no fly ash or microsilica in them [8]. Also, the results of the permeability test indicate a significant increase in resistance against chloride ion penetration for concrete containing fly ash and microsilica. In addition, the results of the test indicate a significant increase in resistance to chloride ion penetration in the case of concrete containing fly ash and microsilica. Siddique has pointed out that the use of microsilica in concrete eliminates weak interfacial areas by strengthening the bond between cement paste and aggregates and forming structures with less porosity and more homogeneity. This has the effect of increasing the compressive strength of concrete [9]. Based on what we have discussed above, one of the main objectives of this study is to assess the amount of corrosion seen in concrete piers mentioned above and determine the role of microsilica in increasing their compressive strength and reducing their corrosion.

Li Victor C. developed ECC in 1993 at the University of Michigan (U.S.A.) [10]. The ECC is a distinct class of HPFRCC (High-performance fiber reinforced cementitious composites) based on the micromechanics of fiber-matrix bond. ECC does not consist of coarse aggregates because of their effect on the ductile behavior of cementitious composites. ECC depicts high ductility when reinforced with a sufficient amount of discontinuous polymeric fibers. Different parameters and slip hardening behavior of fiber with matrix and proper selection of materials and process are responsible for ductile behavior of ECC. The development of ECC from FRC was made by blending and interfacing the properties of fibers and matrix. The purpose of blending the matrix and interface in ECC is to optimize the materials used in the mix. Therefore, the composite failure will convert from brittle to ductile failure. So, the role of fibers and binding material replacement is significant in ECC behaviors [11-13]. ECC belongs to the broad class of fiber reinforced concrete (FRC) [14], as it contains fiber in a cementitious matrix. The tensile ductility, the strain capacity at peak strength, of ECC is typically two orders of magnitude higher than that of normal concrete, while its compressive strength ranges from a low of a few MPa (e.g., a fire-resistive highly insulative ECC for steel protection [15] to over $200 \mathrm{MPa}$ (ultra-high- strength ECC designed for impact and blast resistance). Different types of mineral admixtures were used to replace fly ash, silica sand, and cement in ECC. Also, few researchers used lightweight aggregates in the ECC to improve the hardened properties. Meng et al. has used local dune sand as a replacement for silica sand [16]. It was observed that compressive strength was almost the same, tensile strain capacity decreased, and ultimate tensile and flexural strength increased compared to standard ECC. Silica sand can be replaced by Recycled concrete fines (RCF) [17].

In the present study, the ECC concrete and microsilica $(10 \%$ and $15 \%$ ) are used to investigate their performance on reduction of a corrosion problem in piers P3 \& P4 in Imam Khomeini petrochemical. Three tests, including compressive strength, corrosion intensity, and penetration rate, have been performed. The results show that the microsilica $15 \%$ is the appropriate choice to overcome the corrosion in piers P3 \& P4 in Imam Khomeini petrochemical.

\section{Concrete Corrosion}

The present study aims to investigate the causes of concrete corrosion in the P3 \& P4 piers of in Imam Khomeini petrochemical and provide a solution to prevent it. Bandar Imam Petrochemical Company is located on a land area of about 270 hectares, on the northwest side of the Persian Gulf in Khuzestan province, $105 \mathrm{~km}$ southeast of Ahvaz and 84 $\mathrm{km}$ east of Abadan, Bandar-e- Mahshahr city. The wharves in this facility have suffered severe corrosion due to the penetration of chloride ions. An image of severely corroded rebar is shown in Figure 1.

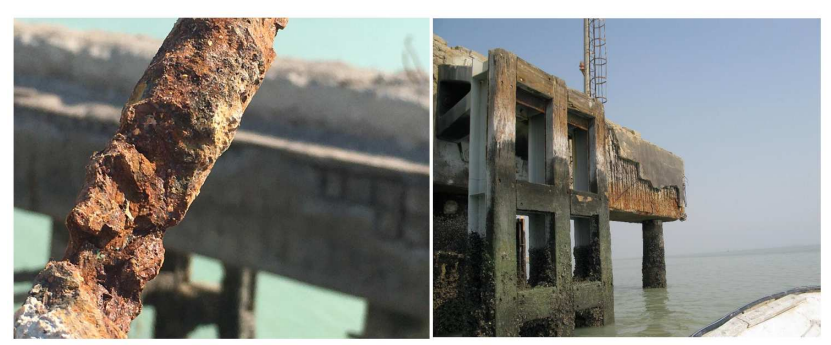

Figure 1. An image of rebar corroded (a) rebar and (b) piers of the P3\& P4 piers of Imam Khomeini petrochemical.

\section{Preparing the Chloride Ion Penetration Profile}

Penetration of chloride ions is the main agent of corrosion onset in reinforcements buried in concrete in most offshore structures. Therefore, it is of particular importance to study the concrete resistance to chloride ion penetration. Chloride ions enter into the concrete both from the outside environment, by contact with contaminated soil or seawater, and from the internal environment using calcium chloridebased accelerator additives or by using contaminated materials with chloride ions. It is well-known that the mechanisms of chloride ion penetration into concrete are due 
to the great importance of chloride ion penetration as an essential factor in reducing the useful life of concrete structures. It should be noted that the penetration of such ions into concrete is not only affected by one factor but by several factors (ionic release, capillary absorption, and suction, permeability, migration in the environment containing chloride ions) simultaneously involved in this [18]. Effects of corrosion on the properties of materials that result from the penetration of chloride ions include the deterioration of such properties (cover), limited concrete (core), longitudinal and transversal reinforcements, and connection between concrete and steel.

The onset time of corrosion and corrosion surface (i.e., structure deterioration relating to the process of reinforcement corrosion) consists of three stages. The first stage is connected with diffusion, a process in which chloride ions disperse on reinforcement surfaces; the second stage concerns the development from the onset time of corrosion until concrete begins to crack, and the third stage has to do with deterioration.

What is presented in this paper is a model of chloride ion corrosion based on Fick's second law in order to simulate the theory and mathematics of the steps mentioned above. The concentration of concrete chloride is a function of depth and time according to Fick's second law and a one-dimensional solution based on developed models [19].

$$
c(x, t)=c_{s}\left[1-\operatorname{erf}\left(\frac{x}{2 \sqrt{D_{c}}} \times t\right)\right]
$$

where, $c(x, t), c_{s}, D_{c}, x, t$, and erf denote the concrete chloride concentration, surface chloride concentration, concrete chloride diffusion coefficient, depth of concrete surface, time, error function, respectively. When chloride concentration on the surface of the reinforcement reaches a critical level, reinforcement corrosion starts. Various functions have been introduced for critical chloride concentration based on existing environmental conditions. The function proposed for this study is connected with a particular region near the Persian Gulf.

In this study, the onset time of corrosion has been proposed as a result of laboratory studies (base on simulated environmental conditions prevailing in the Persian Gulf and the Oman Sea), and experimental studies of the actual corrosive environmental conditions in southern regions of Iran have been done [20]. This can be represented as follows:

$$
T_{\text {corr }}=0.75 C_{1}\left(d_{c} / B_{1}\right)
$$

where, $T_{c o r r}$, and $d_{c}$ are respectively onset time of corrosion (years) and thickness of steel bar coat (mm). Besides, $B_{1}$ and $C_{1}$ and are constants. Note that the coefficients $B_{1}$ and $C_{1}$ depend on the ratio of cement to water and the percentage of microsilica used in designing the concrete mix. The diameter of this mix of reinforcement in the RC decreases over time as a result of corrosion. The equation given below is meant to calculate the reduction of the steel rod's corrosion diameter based on the calculated corrosion onset [21]. Thus:

$$
d_{b}=d_{b i}-1.508(1-w / c)-\frac{1.64}{d_{c}}\left(t-T_{c o r r}\right) 0.71
$$

where, $d_{b}, d_{b i}$, and $w / c$ are reduced steel bar diameter, initial diameter of steel bar, and water-cement ratio, respectively. The amount of corrosion $\left(\Delta_{\text {Corr }}\right)$ in terms of reduction of reinforcement diameter is defined as follows,

$$
\Delta_{c o r r}=\frac{d_{2 b}-d_{2 b i}}{d_{2 b i}} \times 100
$$

As can be verified, first, the corrosion occurs in the bar, and then, owing to the expansion of the corrosion products, cracking takes place in the cover and core concrete. Based on the preceding remarks, one of the most important tests for determining the quality of concrete is to prepare a penetration profile of chloride ions in the depth of concrete. For the

\begin{tabular}{|c|c|c|c|c|c|}
\hline Row & Test position & Test code & Vertical k $\Omega / \mathrm{cm}$ & Horizontal k $\Omega / \mathrm{cm}$ & Diagonal $\mathrm{k} \Omega / \mathrm{cm}$ \\
\hline 1 & Wharf $3^{\text {th }}$ Part $1 . \mathrm{S}$ & SR-P-01 & 65 & 62 & 67 \\
\hline 2 & Wharf $3^{\text {th }}$ Part 1 . A & SR-P-02 & 18 & 16 & 17 \\
\hline 3 & Wharf $3^{\text {th }}$ Part 2. S & SR-P-03 & 33 & 34 & 39 \\
\hline 4 & Wharf $3^{\text {th }}$ Part 2. A & SR-P-04 & 84 & 95 & 84 \\
\hline 5 & Wharf $4^{\text {th }}$ Part $1 . \mathrm{S}$ & SR-P-05 & 97 & 150 & 167 \\
\hline 6 & Wharf $4^{\text {th }}$ Part 1. A & SR-P-06 & 307 & 327 & 300 \\
\hline 7 & Wharf $4^{\text {th }}$ Part 2. S & SR-P-07 & 53 & 70 & 84 \\
\hline 8 & Wharf $4^{\text {th }}$ Part 3. A & SR-P-08 & 66 & 94 & 98 \\
\hline
\end{tabular}
purposes of this study, our tests were conducted by following the ASTM C 1152 standard method, as explained in Table 1.

Table 1. Test results for determination of concrete electrical resistance.

\section{Materials and Methods}

A mixture of river-type sand and crushed-type gravel was prepared (with a specific weight of $2560 \mathrm{~kg} / \mathrm{m}^{3} 2650 \mathrm{~kg} / \mathrm{m}^{3}$, respectively). A consumable aggregate was also prepared from Omid Crushed Sand Company situated near Shooshtar,
Iran, at a distance of about $195 \mathrm{~km}$ from Mahshahr. The specifications of cement, superplasticizer and microsilica used for samples are given as follows.

\subsection{Cement Type}

The consumable cement was considered type-II, Tehran Iran Cement Factory, with a grade of $400 \mathrm{~kg} / \mathrm{m}^{3}$. The cement 
chemical characteristics are given in Table 2.

Table 2. Chemical characteristics of consumable cement.

\begin{tabular}{lllllllll}
\hline Chemical composition & $\mathbf{S i O}_{2}$ & $\mathbf{A l}_{2} \mathbf{O}_{3}$ & $\mathbf{S O}_{3}$ & $\mathbf{F e}_{2} \mathbf{O}_{3}$ & $\mathbf{C a O}$ & $\mathbf{M g O}$ & $\mathbf{C}_{3} \mathbf{S}$ & $\mathbf{C}_{2} \mathbf{S}$ \\
\hline Percentage & 21.97 & 4.26 & 1.65 & 3.55 & 64.56 & 2.33 & 50.68 & 24.76 \\
\hline
\end{tabular}

\subsection{Superplasticizer Additive}

A concrete superplasticizer is a type of chemical additive with a water-reducing function. The main effect of such an additive is to increase fluidity and slump in a constant amount of water or to decrease water in a constant amount of concrete. For our purposes, we used Structuro 335, made by
Fosroc International Limited co., which is composed of a specific polymer, i.e., Carboxylic ether, with long lateral chains. Such composition will dramatically enhance the dispersion of cement grains. As a result, it is suitable for offshore structures and corrosive environments. The specifications of the superplasticizer additive used in this study are listed in Table 3.

Table 3. Chemical characteristics of superplasticizer additive.

\begin{tabular}{ll}
\hline Characteristic & Description \\
\hline Appearance & Liquid, bright yellowish-red \\
Volumetric weight & $1.10 \mathrm{~kg} / \mathrm{L} @ \mathrm{~T}=20^{\circ} \mathrm{C}$ \\
$\mathrm{PH}$ & 6.5 \\
$\mathrm{Chloride}$ contents & Less than $0.1 \%$ \\
Alkaline material content & Usually less than the equivalent of $1.5 \mathrm{gr}^{\circ} \mathrm{Na}_{2} \mathrm{O}$ per liter of this product \\
\hline
\end{tabular}

\subsection{Microsilica}

In this study, Azna Iran microsilica with a particle density of $2200 \mathrm{~kg} / \mathrm{m}^{3}$ was used. Table 4 presents the results of the chemical analysis of this microsilica.

Table 4. Chemical properties of microsilica.

\begin{tabular}{|c|c|c|c|c|c|c|}
\hline Chemical composition & $\mathrm{SiO}_{2}$ & $\mathbf{A l}_{2} \mathrm{O}_{3}$ & $\mathrm{Fe}_{2} \mathrm{O}_{3}$ & $\mathrm{CaO}$ & MgO & $\mathrm{SO}_{3}$ \\
\hline Percentage & 95.1 & 1.32 & 0.87 & 0.49 & 0.97 & 0.1 \\
\hline
\end{tabular}

\subsection{Mixing Ratios}

In this study, four specimens, i.e., microsilica $10 \%$, microsilica $15 \%$, ECC, and control, were made for the sake of comparison. The superplasticizers $4 \%$, water to cement ratio of $38 \%$ were used for all four specimens. The objective was to achieve a suitable slump in different designs in conformity with the aim of this study, that is, the application of microsilica to improve mechanical properties, increase durability, and reinforce concrete compressive strength in offshore piers. This was followed by making a control sample made and tested from a cement of a mixed grade. The number of concrete mixtures studied was referred to as $\mathrm{M} * \mathrm{~S} * \mathrm{~W} *$, and $\mathrm{E}^{*}$ where $\mathrm{M}$ indicates microsilica, $\mathrm{S}$ represents superplasticizer, $\mathrm{W}$ stands for water-to-cement ratio, and E stands for ECC.

As shown in Tables 5-7, based on granulations of three types of Shootar materials, the most suitable mixing design that agrees well with the specifications was selected. The design had the following ingredients: (1) crushed gravel (12$25) \mathrm{mm}, 30 \%$ by weight; (2) broken gravel (5-19) mm, $30 \%$ by weight; (3) natural washed sand $(0-8), 40 \mathrm{~mm}$ by weight; (4) the mixing plan is done according to the specifications shown in Table 5; (5) consumable cement is considered typeII from Tehran- Iran cement factory having a $400 \mathrm{~kg}$ per cubic meter grade; (6) the water-cement ratio $38 \%$ obtained with an average slump of $65 \mathrm{~mm}$ from Mahshahr-Iran water. It must be pointed out that the mixing scheme was drawn up on the basis of specifications seen in Table 5 .

Table 5. Mix schemes used in the present study.

\begin{tabular}{|c|c|c|c|c|c|c|}
\hline Mixing scheme & $\mathrm{W} / \mathrm{C}(\%)$ & Slump (cm) & Sand (kg) & Microsilica (Kg) & Cement (Kg) & Grain (Kg) \\
\hline Control concrete & 0.38 & 5 & 1020 & - & 450 & 700 \\
\hline Microsilica (10\%) & 0.38 & 5 & 1020 & 90 & 360 & 700 \\
\hline Microsilica (15\%) & 0.38 & 5 & 1020 & 130 & 320 & 700 \\
\hline ECC & 0.38 & 5 & 1020 & - & 450 & 700 \\
\hline
\end{tabular}

Table 6. Results of specific weight, dry volume unit weight, and materials water absorption.

\begin{tabular}{lllll}
\hline Description & Appearance specific weight $\left(\mathbf{g r} / \mathbf{c m}^{3}\right)$ & Real specific weight $\left(\mathbf{g r} / \mathbf{c m}^{3}\right)$ & Dry volume unit weight $\left(\mathbf{g r} / \mathbf{c m}^{3}\right)$ & Water absorption $(\mathbf{\%})$ \\
\hline Gravel 12-25 & 2.710 & 2.645 & 1.39 & 0.86 \\
Gravel 5- 19 & 2.722 & 2.66 & 1.5 & 1.04 \\
Sand 0- 8 & 2.712 & 2.604 & 1.59 & 1.53 \\
\hline
\end{tabular}


Table 7. Results of abrasion percentage using the Los Angeles and sand equivalence method.

\begin{tabular}{|c|c|c|c|c|c|}
\hline Description of specimens & Cycle Drop & Abrasion-weighing & Permissible limits of abrasion & sand equivalence & Permissible limits of sand equivalence \\
\hline Gravel 12-25 mm & 500 & 17.6 & 40 & -- & -- \\
\hline Gravel 5- $19 \mathrm{~mm}$ & 500 & 21 & 40 & -- & -- \\
\hline Sand 0- $8 \mathrm{~mm}$ & -- & -- & -- & 0.16 & 75 \\
\hline
\end{tabular}

\section{Preparation of Laboratory Specimens}

\subsection{Making Specimens}

This study aimed to reduce reinforcement corrosion, increase compressive strength, and improve concrete mechanical properties in offshore piers by using ECC and microsilica-based concrete. We used microsilica $(10 \%)$ and superplasticizer $(0.4 \%)$ to achieve our goal. The use of microsilica causes water consumption to increase. This means that concrete with suitable slump and permeability can be obtained by optimizing this parameter. To increase the accuracy of our tests, we considered four different specimens consisting of cement, microsilica, superplasticizer, and water. In Table 8, we have demonstrated nine laboratory specimens used in the present study. It should be noted that the specimens were made with cement Type-II.

Table 8. Determining the percentage of ingredients in concrete laboratory specimens.

\begin{tabular}{llll}
\hline Sample code & W/C & Type of cement & Microsilica (\%) \\
\hline M15S4W38:1 & $38 \%$ & 2 & 15 \\
M10S4W38:4 & $38 \%$ & 2 & 10 \\
E-S4W38:8 & $38 \%$ & 2 & - \\
\hline
\end{tabular}

\subsection{Selection Criteria}

Two standards, ASTM and ASTM C33, were used to make laboratory specimens and select materials. Based on regulation criteria, the maximum grain size was used to make laboratory specimens [22].

\section{Results and Discussion}

\subsection{Compressive Strength}

Cubic specimens in three dimensions $(15 \mathrm{~cm} \times 15 \mathrm{~cm} \times$ $15 \mathrm{~cm}$ ) were made to evaluate the compressive strength of concrete and to conduct an analysis of each specimen to measure compressive strength and corrosion intensity. All specimens were removed from the mold after 24 hours of their manufacture and kept for 72 hours in processing ponds having ordinary water at a normal temperature $\left(20\right.$ to $\left.25^{\circ} \mathrm{C}\right)$. Afterward, the specimens were transferred to the seawater in order to test them for corrosion. The results of the compressive strength experiment are shown in Table 9.

Table 9. The results of compressive strength tests on concrete specimens for 28 days.

\begin{tabular}{llllll}
\hline Specimen code & Length $(\mathbf{c m})$ & Width $(\mathbf{c m})$ & Height $(\mathbf{c m})$ & Maximum force $(\mathbf{k g})$ & Compressive strength $\left(\mathbf{k g} / \mathbf{c m}^{2}\right)$ \\
\hline Control & 151 & 15.1 & 15.1 & 98120 & 430 \\
M10S4w38:3 & 15.2 & 15.1 & 15.1 & 155530 & 593 \\
M15S4w38:4 & 15.1 & 15 & 15 & 161600 & 604 \\
E-S6W38:7 & 15.1 & 15 & 15 & 129020 & 530 \\
\hline
\end{tabular}

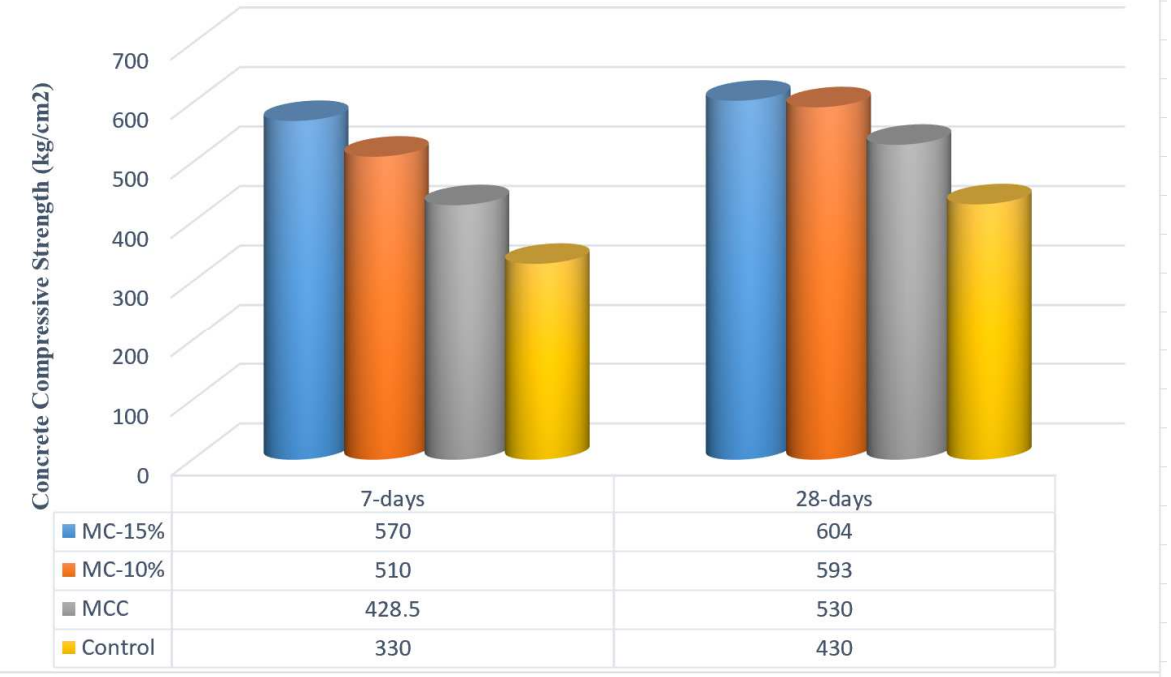

Figure 2. Concrete compressive strength for 7- and 28-days test. 
Figure 2 shows the compressive strength of the four concretes used for the 7- and 28-day tests. As expected, for all four cases, the 28-day compressive strength was greater than that of the 7-day test. As can be seen from the figure, the highest compressive strengths are related to microsilica $15 \%$, microsilica $10 \%, \mathrm{ECC}$, and control sample, respectively. As the amount of microsilica increases from $10 \%$ to $15 \%$, the compressive strength increases from 510 to 570 (about 11\%). On the other hand, the compressive strength of microsilica $15 \%$ is about $12 \%$ and $28 \%$ higher than ECC and control concrete, respectively. Due to the higher compressive strength of $15 \%$ microsilica concrete, it is expected that the permeability and corrosion rate will be better than the other three samples.

\subsection{Penetration Test}

The water penetration test was performed on the samples after 28 days of treatment according to BS (Testing hardened concrete, 2009). The results are shown in Figure 3. From this figure, it can be seen that the highest water penetration is related to the control concrete $(24.5 \mathrm{~mm})$. As mentioned earlier, microsilica concrete allows less water penetration due to its higher compactness, and the diagram shows that the water penetration depth in microsilica $15 \%$, microsilica $10 \%$, and ECC are respectively $13.4 \mathrm{~mm}, 14.6 \mathrm{~mm}$, and $17.3 \mathrm{~mm}$.

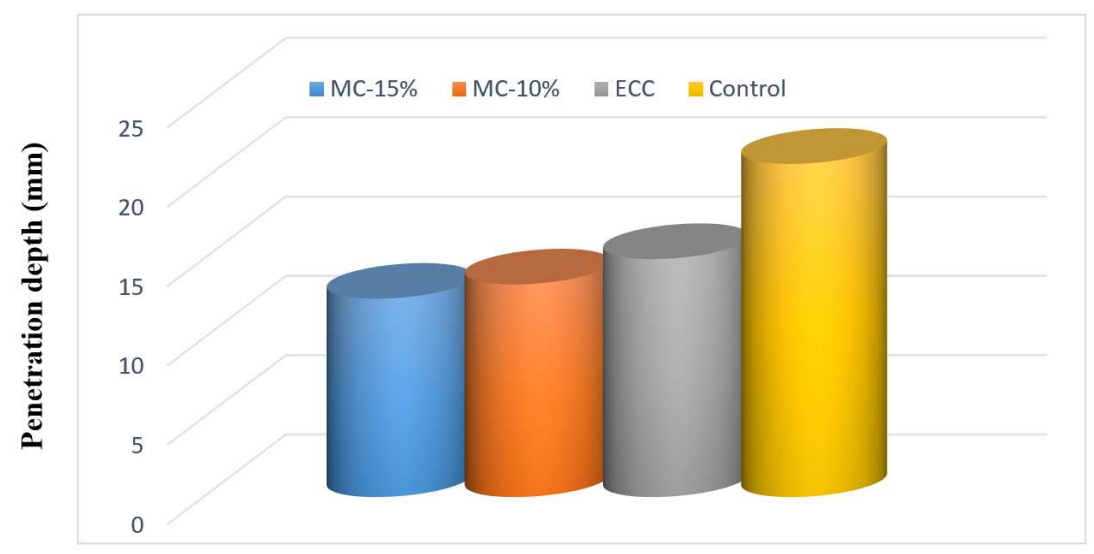

Figure 3. Corrosion rate of concrete specimens at different times.

\subsection{Corrosion Test}

In this study, concrete specimens were kept in a laboratory in the Persian Gulf environment for 18 months. Corrosion tests were then conducted on the laboratory samples 80 times for 4.5 months, and the test results were compared with each other. The range of corrosion intensity used in the present study and their interpretation are listed in Table 10.

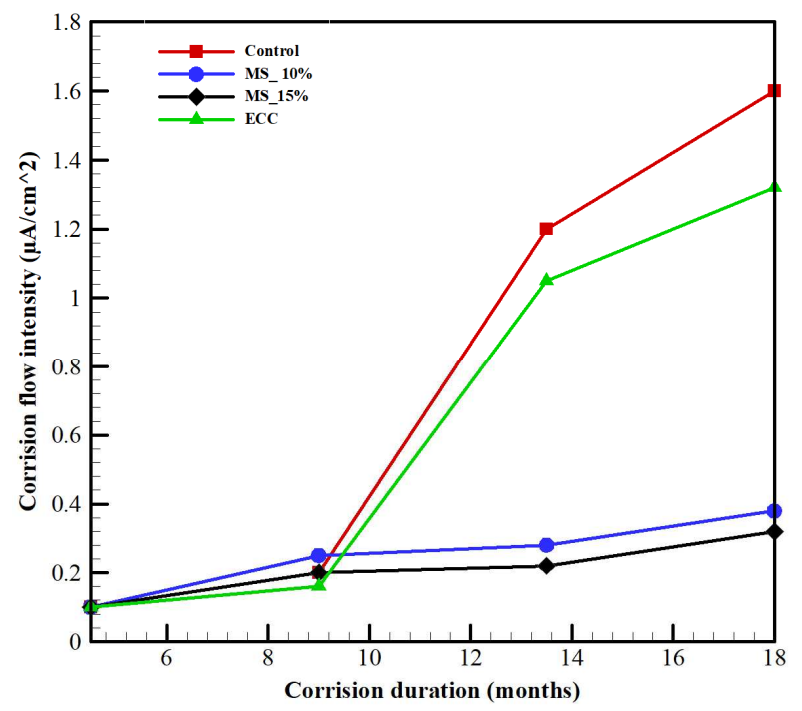

Figure 4. Corrosion rate of concrete specimens at different times.
Table 10. Ranges of corrosion intensity and their interpretation [23].

\begin{tabular}{ll}
\hline Extent of Corrosion & Corrosion Current Density $\left(\boldsymbol{\mu} \mathbf{A} / \mathbf{c m}^{2}\right)$ \\
\hline Passive condition & $I_{\text {corr }}<0.1$ \\
Low to moderate corrosion & $0.1<I_{\text {corr }}<0.5$ \\
Moderate to high corrosion & $0.5<I_{\text {corr }}<1$ \\
High corrosion & $I_{\text {corr }}>1$ \\
\hline
\end{tabular}

The results of the corrosion test are shown in Figure 3. After 9 months, the lowest amount of corrosion is related to ECC concrete, which is due to the high flexibility of this type of concrete and its resistance to cracking. However, from this time onwards, as the cracks appeared, the resistance of ECC concrete against penetration decreases sharply and follows the same trend of corrosion intensity exactly as the control sample. After 18 months, it reaches its highest value $(1.3 \mu \mathrm{A} /$ $\mathrm{cm}^{2}$ ), which according to the data in Table 10, this concrete is in a state of high corrosion. On the other hand, concrete containing microsilica (both $10 \%$ and $15 \%$ ) showed a low corrosion intensity after 18 months due to high compressive strength. The corrosion intensities of $15 \%$ and $10 \%$ microsilica are $0.21 \mu \mathrm{A} / \mathrm{cm}^{2}$ and $0.28 \mu \mathrm{A} / \mathrm{cm}^{2}$, respectively, which according to Table 10, both concrete samples are in the category of low to medium corrosion.

\section{Conclusions}

In the present study, the causes and extent of corrosion observed in piers $3 \& 4$ in Mahshar petrochemical were determined and evaluated. Four different concretes were 
used, including microsilica 15\%, microsilica 10\%, ECC, and control. Then three tests (compressive strength, penetration, and corrosion) were performed to determine the conditions of concrete piers in terms of reinforcement corrosion. The outstanding results are highlighted as follows:

1) The highest compressive strengths are related to microsilica $15 \%$, microsilica $10 \%$, ECC and control sample, respectively.

2) With increasing the contents of microsilica increases from $10 \%$ to $15 \%$, the compressive strength increases about $11 \%$.

3) Microsilica concrete allows less water penetration due to its higher compactness. Water penetration depth in microsilica $15 \%$, microsilica $10 \%$, and ECC are respectively $13.4 \mathrm{~mm}, 14.6 \mathrm{~mm}$, and $17.3 \mathrm{~mm}$.

4) Because of flexibility and crack-resistant properties, ECC concrete, in the first 9 months, performs better in terms of penetration. However, as the cracks occurred, the corrosion intensity dramatically increases.

5) The corrosion intensities of $15 \%$ and $10 \%$ microsilica are in the range of $0.1-0.5 \mu \mathrm{A} / \mathrm{cm}^{2}$, which according to Table 10, both fall in the category of low to medium.

\section{Nomenclature}

This list is located before the list of references and should include English symbols followed by Greek symbols in alphabetical order as the following examples:

$c(x, t) \quad$ concrete chloride concentration, $\%$

$c_{s} \quad$ surface chloride concentration, $\%$

$x \quad$ concrete chloride diffusion coefficient, $\mathrm{cm}^{2} / \mathrm{s}$

$D_{c} \quad$ depth of concrete surface, $\mathrm{cm}$

erf error function

$t$ time, s

$T_{\text {corr }}$ onset time of corrosion, year

$d_{c} \quad$ thickness of steel bar coat, $\mathrm{mm}$

$B_{1}, C_{1}$ constants

$d_{b} \quad$ reduced steel bar diameter, $\mathrm{mm}$

$d_{b i} \quad$ initial diameter of steel bar, $\mathrm{mm}$

$w / c \quad$ water-cement ratio, $\%$

$d_{b} \quad$ reduced steel bar diameter, $\mathrm{mm}$

$V \quad$ pulse rate, $\mathrm{m} / \mathrm{s}$

$E_{d} \quad$ mechanical modulus of elasticity concrete, $\mathrm{MN} / \mathrm{m}^{2}$

Greek symbols

$\Delta_{\text {Corr }}$ amount of corrosion, $\%$

$v \quad$ Poisson's ratio

$\rho \quad$ concrete density, $\mathrm{kg} / \mathrm{cm}^{2}$

Subscript

Corr Corrosion

$s \quad$ Surface

c coat

\section{Acknowledgements}

The authors are grateful to the Imam Khomeini Port managers for providing facilities where part of this work was carried out.

\section{References}

[1] B. He, Y. Gao, L. Qu, K. Duan, W. Zhou, and G. Pei, "Characteristics analysis of self-luminescent cement-based composite materials with self-cleaning effect," Journal of Cleaner Production, vol. 225, pp. 1169-1183, 2019.

[2] X. He, Z. Zheng, J. Yang, Y. Su, T. Wang, and B. Strnadel, "Feasibility of incorporating autoclaved aerated concrete waste for cement replacement in sustainable building materials," Journal of Cleaner Production, vol. 250, p. $119455,2020$.

[3] D. Antunes, R. Martins, R. Carmo, H. Costa, and E. Júlio, "A solution with low-cement-lightweight concrete and high durability for applications in prefabrication," Construction and Building Materials, vol. 275, p. 122153, 2021.

[4] L. Fedrizzi, F. Azzolini, and P. L. Bonora, "The use of migrating corrosion inhibitors to repair motorways' concrete structures contaminated by chlorides," Cement and Concrete Research, vol. 35, no. 3, pp. 551-561, 2005.

[5] J. Liu, H. Huang, Z. J. Ma, and J. Chen, "Effect of shear reinforcement corrosion on interface shear transfer between concretes cast at different times," Engineering Structures, vol. 232, p. 111872, 2021.

[6] A. Bagheri, H. Zanganeh, H. Alizadeh, M. Shakerinia, and M. A. S. Marian, "Comparing the performance of fine fly ash and silica fume in enhancing the properties of concretes containing fly ash," Construction and building materials, vol. 47, pp. 1402-1408, 2013.

[7] A. Pandey and B. Kumar, "Evaluation of water absorption and chloride ion penetration of rice straw ash and microsilica admixed pavement quality concrete," Heliyon, vol. 5, no. 8, p. e02256, 2019.

[8] E. Moffatt and M. Thomas, "Performance of 25-year-old silica fume and fly ash lightweight concrete blocks in a harsh marine environment," Cement and Concrete Research, vol. 113, pp. 65-73, 2018.

[9] R. Siddique, "Utilization of silica fume in concrete: Review of hardened properties," Resources, Conservation and Recycling, vol. 55, no. 11, pp. 923-932, 2011.

[10] V. C. Li, T. Kanda, Engineered cementitious composites for structural applications, J. Mater. Civ. Eng. 10 (2) (1998) 66-69 1561(1998)10:2(66).

[11] V. C. Li, Engineered cementitious composites (ECC) material, structural, and durability performance, in: E. Nawy (Ed.), Concrete Construction Engineering Handbook, CRC Press, 2007(Chapter 24).

[12] V. C. Li, On Engineered Cementitious Composites (ECC)-A review of the material and its applications, J. Adv. Concr. $\begin{array}{lllll}\text { Technol. } & 1 & \text { (3) } & \text { (2003) } & \text { 215-230 }\end{array}$ https://doi.org/10.3151/jact.1.215.

[13] M. Maalej, S. T. Quek, S. F. U. Ahmed, J. Zhang, V. W. J. Lin, K. S. Leong, Review of potential structural applications of hybrid fiber engineered cementitious composites, Constr. Build. Mater. 36 (2012) 216-227 https://doi.org/10.1016/j. conbuildmat.2012.04.010. 
[14] Bentur, A., Mindess, S.: Fibre Reinforced Cementitious Composites, 2nd edn. E \& FN Spon, London (2007)

[15] Zhang, Q., Ranade, R., Li, V. C.: Feasibility study on fireresistive engineered cementitious composites. ACI Mater. J. 111(1-6), 1-10 (2014)

[16] D. Meng, T. Huang, Y. X. Zhang, C. K. Lee, Mechanical behaviour of a polyvinyl alcohol fibre reinforced engineered cementitious composite (PVA-ECC) using local ingredients, $\begin{array}{lllll}\text { Constr. } \quad \text { Build. } & \text { Mater. } 141 \quad \text { (2017) } 259-270\end{array}$ https://doi.org/10.1016/j.conbuildmat.2017.02.158.

[17] L. Junxia, E. H. Yang, Macroscopic and micro structural properties of engineered cementitious composites incorporating recycled concrete fines, Cement Concr. Compos. $78 \quad$ (2017) 33-42 https://doi.org/10.1016/j.cemconcomp.2016.12.013.

[18] A. R. Baqheri, H. Zanganeh, H. Samadzad, and A. L. A. H. Kiani, Assessing The Durability Of Binary And Ternary Concretes Using Rapid Chloride Resistance Test And The Accelerarted Rebar Corrosion Test," presented at the International Congress On Durability Of Concrete, 2012.
[19] C. Q., Li, J. J., Zheng, "Propagation of reinforcement corrosion in concrete and its effects on structural deterioration", Magazine of Concrete Research, 57(5) (2005) 261-71.

[20] H. R., Ashrafi, A. A., Ramezanianpour, "Model Presentation for the Chloride Diffusion in Silica Fume Concretes Based on the Experimental Results", Amirkabir University of Technology, Tehran, 2007.

[21] J. Zhong, Seismic fragility estimates for corroded reinforced concrete bridge structures with two-column bents. Texas $A \& M$ University, 2008.

[22] ASTM C33-03, 2013- Standard Specification for Concrete Aggregates, Annual Book of ASTM Standards, vol. 04.02.

[23] P. Gu, J. Beaudoin, M.-H. Zhang, and V. Malhotra, "Performance of reinforcing steel in concrete containing silica fume and blast-furnace slag ponded with sodium-chloride solution," Materials Journal, vol. 97, no. 3, pp. 254-262, 2000 . 